\title{
BMJ Open Period prevalence, risk factors and consequent injuries of falling among the Saudi elderly living in Riyadh, Saudi Arabia: a cross-sectional study
}

\author{
Faisal Yousef Almegbel, ${ }^{1,2}$ Ibrahim Muthyib Alotaibi, ${ }^{1,2}$ Faisal Ahmed Alhusain,, ${ }^{1,2}$ \\ Emad M Masuadi, ${ }^{3}$ Salma Lafyan Al Sulami, ${ }^{1}$ Amairah Fahad Aloushan, ${ }^{1}$ \\ Bashayer Ibrahim Almuqbil ${ }^{1}$
}

To cite: Almegbel FY, Alotaibi IM, Alhusain FA, et al. Period prevalence, risk factors and consequent injuries of falling among the Saudi elderly living in Riyadh, Saudi Arabia: a cross-sectional study. BMJ Open 2018;8:e019063. doi:10.1136/ bmjopen-2017-019063

- Prepublication history for this paper is available online. To view these files, please visit the journal online (http://dx.doi. org/10.1136/bmjopen-2017019063).

FYA, IMA and FAA contributed equally.

Received 8 August 2017 Revised 26 0ctober 2017 Accepted 28 November 2017

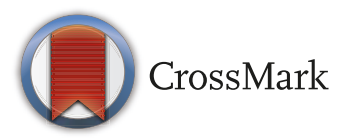

${ }^{1}$ College of Medicine, King Saud bin Abdulaziz University for Health Sciences, Riyadh, Saudi Arabia

${ }^{2}$ King Abdullah International

Medical Research Center,

Riyadh, Saudi Arabia

${ }^{3}$ Research Unit, Medical

Education Department, College

of Medicine, King Saud bin

Abdulaziz University for Health

Sciences, Riyadh, Saudi Arabia

Correspondence to

Dr Faisal Ahmed Alhusain;

FaisalAAlhusain@gmail.com

\section{ABSTRACT}

Objectives Approximately $28 \%$ to $35 \%$ of people aged 65 and over fall each year. The consequent injuries of falls are considered a major public health problem. Falls account for more than half of injury-related hospitalisations among old people. The aim of this study was to measure a 1-year period prevalence of falling among old people in Riyadh, Saudi Arabia. In addition, this study described the most common risk factors and consequent injuries of falls. Setting and participants A cross-sectional survey was carried out in Riyadh, using a convenient sampling. The targeted population were Saudi citizens who were 60 years or above. Over a 6-month period, 1182 individuals were sampled ( 545 men and 637 women).

Results The 1-year prevalence of falling among old Saudis ( $>=60$ years) was $49.9 \%$. Our results show that $74 \%$ of the participants who experienced falls had postfall injuries. Old participants who were uneducated and those with middle school certification were associated with falls (adjusted OR (aOR) 1.72; 95\% Cl 1.15 to 2.56, a0R $1.81 ; 95 \% \mathrm{Cl} 1.15$ to 2.85 , respectively). Those who live in rented houses had a higher risk of falls. Interestingly, having a caregiver was significantly associated with more falls (aOR 1.39; $95 \% \mathrm{Cl} 1.08$ to 1.79). However, not using any medications was significantly related to fewer falls. In addition, old individuals using walking aids were more likely to fall than those who did not. Participants who mentioned 'not having stressors were associated with less frequent falls (aOR $0.62 ; 95 \% \mathrm{Cl} 0.39$ to 0.97 ). Cerebrovascular accidents were strongly associated with falls with an estimated OR of 2.75 (95\% Cl 1.18 to 6.43). Moreover, osteoporosis, poor vision and back pain were found to be predictors for falls among the elderly.

Conclusion $49.9 \%$ of elderly Saudis had experienced one or more falls during a 12-month period. Several preventable risk factors could be addressed by routine geriatric assessment. Research on the impact of these risk factors is needed.

\section{INTRODUCTION}

There is no exact definition of the word 'elderly' as this concept is perceived differently in different cultures and generations.
Strengths and limitations of this study

- Limited studies in middle east discuss the geriatrics issues, specifically falls among this age category. To the best of our knowledge, this is the first study to be done about falls among elderly Saudis.

- We did not directly ask the elderly (the elderly was approached through their relatives) because of the difficulty with older people the research team encountered during the piloting period.

- Some variables were not included in the analysis or listed in the data collection form to avoid questionnaire fatigue for the participants, and thereby maintain a high retention rate.

- This is a cross-sectional study, in which we included all falls during a 12-month period, a period susceptible to a recall bias.

- Self-reported answers may be exaggerated and respondents may be too embarrassed to reveal private details; various biases may affect the results in this study.

An individual can be socially, economically or chronologically viewed as elderly. The age of 60 years is used as the reference point for someone to be described as elderly by the United Nations (UN). ${ }^{1}$ In 2012, there were around 810 million elderly people alive worldwide; two-thirds of those were living in developing countries. It was postulated that this number will reach two billion by 2050 . As for Saudi Arabia, in 2012, there were 4.9\% (1.4 million) of the Saudi population over the age of 60 years. This same report predicted that this number will reach up to $21.8 \%$ (10 million) by $2050 .^{1}$

Falls are defined as "inadvertently coming to rest on the ground, floor or other lower level, excluding intentional change in position to rest (on) furniture, walls or other objects". ${ }^{2}$ Approximately $28 \%$ to $35 \%$ of people aged 65 and over fall each year. ${ }^{2}$ The 
consequent injuries of falls are considered major public health problems. Falls account for more than half of injury-related hospitalisations among elderly people. The major underlying causes of hospital admissions include hip fractures, traumatic brain injuries and upper limb injuries. ${ }^{2}$ According to the UN Population Fund, around $20 \%$ of elderly people will die within a year following a hip fracture. ${ }^{1}$ In addition, unintentional falls are the fifth leading cause of death in elderly people. ${ }^{3}$

Falls may lead to postfall syndrome. ${ }^{4}$ Most elderly people who had previous falls have become dependent in terms of taking care of themselves and carrying out their daily activities. ${ }^{15}$ This will surely affect the quality of life among those people in many respects. Moreover, psychological problems are usually common in those who have previously fallen. Almost $70 \%$ of those patients will suffer from stress and the fear of not being able to stand and walk. ${ }^{5}$

A significantly increased risk of falling has been seen in elderly persons with diabetes and hypertension. ${ }^{6}$ The risk is also significantly increased in those with lower limb weakness, balance/gait problems, dizziness and visual disorders. ${ }^{78}$ Education plays a big role in preventing or decreasing the incidence of falls, especially among elderly people. The level of education varies from one community to another. In Saudi Arabia, the population is dramatically increasing; currently, there are about 30 million people living in the kingdom. ${ }^{9}$ This category of people should be educated about the most common risk factors and consequent injuries of falls. Unfortunately, the evidence of falls in older adults in developing countries, including Saudi Arabia, is sparse. ${ }^{10}$

The aim of this study was to measure the prevalence of falling among elderly people in Riyadh, Saudi Arabia. In addition, this study describes the most common risk factors and consequent injuries of falls. Identifying the risk factors of falls will add to our current knowledge about this particular subject, raise awareness and provide for recommendations that will help in reducing the incidence of falls and thereby increase the quality of life among elderly people.

\section{MATERIALS AND METHODS}

\section{Study design, study setting and subjects}

This study was a cross-sectional study. The targeted population were Saudi citizens who were 60 years or above and live in the city of Riyadh, Saudi Arabia. Those who were unable to answer the questions and those with cognitive impairment were excluded from the study. During a 6-month period from January to June 2016, 1182 individuals were reached.

\section{Data collection form}

A data collection form (DCF) was developed as a tool for interviewing the participants. The DCF was pretested on a pilot sample to ensure that the survey was understood correctly by all respondents. The questions in the DCF were categorised into three sections: falling-related questions as remembered by the participant; health-related questions including acute and chronic diseases, number of medications and use of walking aids and demographic questions including age, gender, educational level, income, source of support, marital status, house ownership, smoking and exercise.

\section{Sample size}

The margin of error and confidence level were 3\% and $95 \%$, respectively. Likewise, the response distributionwhich always provides the largest sample size-of prevalence of falls among the elderly was $50 \%$. The minimum recommended size to meet this criterion was 1014 participants. The sample size was calculated using Raosoft, an open source calculator.

\section{Questionnaire piloting}

Each interview took approximately 5 to $15 \mathrm{~min}$, depending on the participant's responses; a positive answer necessitated further inquiries. However, during piloting, when the research team tried to reach out to elderly people in public places and outpatient clinics, completion of the DCF was poor owing to the large number of questions. In addition, many individuals gave negative answers deliberately to prevent further inquiries. To overcome this limitation and generate results as accurately as possible, we created a digital version of the DCF and targeted a different category of people, namely, Saudis who were 18 years old or above and had an elderly relative with the aforementioned inclusion criteria.

\section{Sampling technique}

The research team reached out to them in public places with one question: Do you have a relative 60 years of age or above who lives in Riyadh? If the answer was affirmative, and they were willing to participate, we asked for their names and contact information and provided them with the following instructions. (A link of the DCF will be sent to you. Use it as a tool to direct the questions to your relative, the elderly person. You are merely an interviewer in this process. The answers to the questions found in the link must come from the elderly person only. Write your name as given to the research team member at the beginning of the DCF, so the source of your response can be identified and hence accepted. This link is for your personal use only. Do not send it to anyone unless you inform the research team member.) After completing the form, the interviewer was transferred to a web page with a specific code sent to the research team member. This protocol has been helpful in identifying responses from interviewers who might have entered a different variant of the name given to the research team member. To add to the accuracy measures, after a team member had contacted all the interviewers, their link was turned off and a new one created before continuing the sampling procedure with a further group. 


\section{Data management and analyses}

The Statistical Package for the Social Sciences V.23 (SPSS) was used for data management and analysis. Descriptive statistics were used to assess the baseline demographics; they were carried out by calculating the frequencies and percentages comparing those who had a fall and those who had not. Prevalence was calculated with a $95 \%$ CI. Univariate and bivariate analyses of logistic regression were conducted to investigate risk factors related to falls. The model was run using all predictors at one time to obtain the OR by adjusting for other predictors. The 95\% CI, OR and adjusted OR (aOR) were reported. All tests were considered significant if the $\mathrm{P}$ value was less than 0.05 .

\section{Ethical considerations}

The study was approved by the Institutional Review Board, King Abdullah International Medical Research Centre, Ministry of National Guard Health Affairs, Riyadh, Saudi Arabia. Participants were informed of their right to abstain from participation in the study or to withdraw their consent to participate at any time without reprisal. Data collection forms were accompanied by a cover letter explaining the purpose of the study and clearly stating that answers would be confidential and that anonymity would be guaranteed in the final reports.

\section{RESULTS}

\section{Baseline characteristics of study participants}

Over the study period from January to June 2016, 1182 elderly people were interviewed by the research team. All of the participants were aged between 60 and 111 years (mean $68.8 \pm 9.0$ years, $69.1 \pm 9.4$ years for men and $67.7 \pm 8.7$ years for women). The proportion of men was almost equal to women with slightly more women $(53.9 \%, 647)$. Uneducated participants accounted for $36.3 \%$ (429) and $30.7 \%$ (363) had high school certification. Almost 64\% (752) were married, $32 \%$ (378) were single or widowed and the rest $(4.4 \%, 52)$ were separated. Only $9.6 \%$ (113) of the sample were smokers. Of the participants, $43 \%$ (511) said that they had a caregiver to help them in their activities. About two-thirds of the participants (64.9\%, 766) mentioned they were experiencing psychological stressors. Only $12 \%(145)$ were using no medication while the majority $(47 \%, 555)$ were using four or more types of medication. Dependence on walking aids was not prevalent among the participants, 67\% (795) of whom were not using any walking aid. The sociodemographic characteristics for the participants are listed in table 1.

\section{Prevalence of falls over a 12-month period and fall-related characteristics}

As table 2 and figure 1 show, $49.9 \%$ (590) of elderly Saudis had experienced one or more falls during a 12 -month period (among women 52\% (333); among men $47 \%$ (257)). Most of these individuals (53\% (312)) had fallen once, 179 (30\%) had fallen twice, 73 (12.4\%) had fallen three times and only 17 (2.9\%) had fallen four times. Our results show that $74 \%$ of the participants who experienced falls had postfall injuries. Ten per cent of those injuries caused different types of fractures with leg fractures being accounting for $39 \%$ (39) of total fractures, followed by hip and arm fractures (21\% each (21 each)). Furthermore, $48 \%$ (283) of falls caused bruises. Of disk prolapse cases in those individuals, $5 \%$ were due to a fall. In addition, according to our results, half of those who experienced a fall were unable to independently return to their previous position immediately after falling and $46 \%$ needed a walking aid. Regarding the place where the fall occurred, 77\% (762) had fallen in their homes, $15 \%$ (146) in public places (mosques, streets, malls and elsewhere) and $8 \%$ (79) in other places. Our results show that most falls occurred in bathrooms $(35 \%$ (250)) and at the front door step (20\% (168)). The rest took place in the kitchen, on stairs, in bedrooms and other places. Most of the falls occurred during the afternoon $(30 \%$ (295)), followed by $28 \%$ (277) which occurred in the morning and 23\% (229) in the evening. Falling on their side occurred among 31\% (308) of individuals while 30\% (301) fell face down, 24\% (239) on their back and 13\% (131) on their knees.

\section{Forward stepwise univariate logistic regression analysis of the baseline characteristics' predictors of falls among elderly people}

There was no association between age, gender, income, source of financial support, marital status, smoking or exercise and experiencing a fall. Significantly, participants who were uneducated and those with middle school certification were associated with falls (aOR 1.72; 95\% CI 1.15 to 2.56 , aOR $1.81 ; 95 \%$ CI 1.15 to 2.85 , respectively). Participants who lived in rented houses had a higher risk of falls than participants living in their own houses (aOR 1.56 ; $95 \%$ CI 1.02 to 2.37). Interestingly, having a caregiver was significantly associated with more falls (aOR $1.39 ; 95 \%$ CI 1.08 to 1.79 ). However, not using any medication was significantly related to fewer falls (aOR 0.60; $95 \%$ CI 0.41 to 0.90 ). In addition, elderly people who used walking aids were more likely to fall compared with those who did not. Those who used walkers or frames had significantly more than double the risk of falls (aOR 2.43; $95 \%$ CI 1.28 to 4.62 ) as did those who used walking sticks (aOR 1.54; 95\% CI 1.15 to 2.05). Participants who mentioned 'not having stressors' were associated with less frequent falls (aOR 0.62; 95\% CI 0.39 to 0.97 ). Table 3 summarises the results of forward stepwise univariate logistic regression analysis of the predictors of falls among elderly people.

\section{Forward stepwise univariate logistic regression analysis of} the predictors of falls (comorbidities and conditions) among elderly people

Of participants in this study, $92 \%$ had one or more comorbidities. Diabetes (51.9\%), hypertension (44.9\%), poor vision $(36.2 \%)$ and dyslipidaemia $(33.8 \%)$ were the 
Table 1 Demographic characteristics of the respondents and risk factors associated with falls among elderly Saudis

\begin{tabular}{|c|c|c|c|c|}
\hline \multirow[b]{3}{*}{ Variable } & \multirow[b]{3}{*}{ Category } & \multirow[b]{2}{*}{ Total } & \multicolumn{2}{|l|}{ Falls } \\
\hline & & & No & Yes \\
\hline & & n (\%) & n (\%) & n (\%) \\
\hline \multirow[t]{3}{*}{ Age $($ Mean $\pm S D)$} & $68.8 \pm 9.027$ & & & \\
\hline & Male: $69.13 \pm 9.379$ & & & \\
\hline & Female: $67.68 \pm 8.673$ & & & \\
\hline \multirow[t]{2}{*}{ Gender } & Male & $545(46.1)$ & $288(52.8)$ & $257(47.2)$ \\
\hline & Female & $637(53.9)$ & $304(47.7)$ & $333(52.3)$ \\
\hline \multirow[t]{5}{*}{ Educational level } & Uneducated & $429(36.3)$ & $187(43.6)$ & 242(56.4) \\
\hline & Primary school & $241(20.4)$ & $126(52.3)$ & $115(47.7)$ \\
\hline & Middle school & $149(12.6)$ & $68(45.6)$ & $81(54.4)$ \\
\hline & High school & $163(13.8)$ & $88(54)$ & $75(46)$ \\
\hline & Diploma/Bachelor/Postgraduate & $200(16.9)$ & $123(61.5)$ & $77(38.5)$ \\
\hline \multirow[t]{3}{*}{ Marital status } & Married & $752(63.6)$ & $385(51.2)$ & $367(48.8)$ \\
\hline & Single or widowed & $378(32)$ & $184(48.7)$ & 194(51.3) \\
\hline & Separated & $52(4.4)$ & $23(44.2)$ & 29(55.8) \\
\hline \multirow[t]{4}{*}{ Monthly family income (Saudi Riyal) } & Less than 5000 & $300(25.4)$ & $138(46)$ & $162(54)$ \\
\hline & 5000-9999 & $350(29.6)$ & $173(49.4)$ & $177(50.6)$ \\
\hline & 10000-19999 & $297(25.1)$ & $148(49.8)$ & $149(50.2)$ \\
\hline & More than 19999 & 235 (19.9) & $133(56.6)$ & $102(43.4)$ \\
\hline \multirow[t]{4}{*}{ Source of financial support } & $\begin{array}{l}\text { I support myself, my wife and my } \\
\text { children }\end{array}$ & $364(30.8)$ & $203(55.8)$ & $161(44.2)$ \\
\hline & I support myself & $325(27.5)$ & $143(44)$ & $182(56)$ \\
\hline & Someone else supports me & $414(35)$ & $203(49)$ & $211(51)$ \\
\hline & I support myself and my wife & $79(6.7)$ & $43(54.4)$ & $36(45.6)$ \\
\hline \multirow[t]{2}{*}{ Housing ownership } & Owned & $1069(90.4)$ & $545(51)$ & $524(49)$ \\
\hline & Rented & $113(9.6)$ & $47(41.6)$ & $66(58.4)$ \\
\hline \multirow[t]{2}{*}{ Having a caregiver } & No & $671(56.8)$ & $365(54.4)$ & $306(45.6)$ \\
\hline & Yes & $511(43.2)$ & $227(44.4)$ & $284(55.6)$ \\
\hline \multirow[t]{4}{*}{ Use of walking aid } & Do not use & $795(67.3)$ & $431(54.2)$ & $364(45.8)$ \\
\hline & Walking stick & $279(23.6)$ & $118(42.3)$ & $161(57.7)$ \\
\hline & Walker or frame & $52(4.4)$ & $15(28.8)$ & 37 (71.2) \\
\hline & Wheelchair & $56(4.7)$ & $28(50)$ & $28(50)$ \\
\hline \multirow[t]{3}{*}{ Use of medications (number) } & Do not use any medications & $145(12.3)$ & $88(60.7)$ & 57 (39.3) \\
\hline & $1-3$ & $482(40.8)$ & $262(54.4)$ & $220(45.6)$ \\
\hline & four or more & $555(47)$ & $242(43.6)$ & $313(56.4)$ \\
\hline \multirow[t]{3}{*}{ Stress } & No stress & $416(35.2)$ & $244(58.7)$ & $172(41.3)$ \\
\hline & Some & $659(55.8)$ & $301(45.7)$ & $358(54.3)$ \\
\hline & Substantial & $107(9.1)$ & 47 (43.9) & $60(56.1)$ \\
\hline \multirow[t]{2}{*}{ Cigarette smoking } & No & $1069(90.4)$ & 533 (49.9) & $536(50.1)$ \\
\hline & Yes & $113(9.6)$ & 59 (52.2) & $54(47.8)$ \\
\hline \multirow[t]{2}{*}{ Exercise } & No & $824(69.7)$ & $393(47.7)$ & $431(52.3)$ \\
\hline & Yes & 358 (30.3) & $199(55.6)$ & 159 (44.4) \\
\hline
\end{tabular}

most prevalent. Table 4 and figure 2 detail the forward stepwise univariate logistic regression analysis of the predictors of falls (comorbidities and conditions) among the elderly. Cerebrovascular accident (CVA) was strongly associated with falls with an estimated OR of $2.75(95 \%$ CI 1.18 to 6.43$)$. Moreover, osteoporosis, poor vision and 
back pain were found to be predictors for falls among elderly people (aOR 1.47, 95\% CI 1.07 to 2.01; aOR $1.49,95 \%$ CI 1.14 to 1.93 ; aOR $1.42,95 \%$ CI 1.06 to 1.89 , respectively).

\section{DISCUSSION}

Falls are common among the elderly worldwide with various factors increasing prevalence. Falls usually occur as a result of wide and diverse risk factors, as previous studies have shown. ${ }^{11} 12$ Thus, it is important to know the risk factors contributing to these falls among the elderly living in Saudi Arabia. By investigating and addressing these risk factors, mortality, morbidity, hospital admission and reduced functionality will also be reduced among the elderly. The purpose of this study was to measure the prevalence of falling among elderly people and to identify the most common risk factors and consequent injuries of falls.

The present study reveals a high prevalence of at least one fall in the previous year among the Saudi elderly in Riyadh (49.9\%). This is similar to a local study conducted by Alsaif et al that showed $44.2 \%$ of elderly Saudis had a history of falls. ${ }^{13}$ This $49.9 \%$ prevalence of falling is much higher than that reported in many countries: $28 \%$, $34 \%, 37.4 \%$ and $22 \%$ in England, ${ }^{14}$ Canada, ${ }^{15}$ Ecuador ${ }^{16}$ and USA ${ }^{17}$ respectively. Interestingly, studies from Asian countries showed much lower prevalence rates than other countries: $11 \%$ in China, ${ }^{18} 16 \%$ in Japan, ${ }^{19} 19 \%$ in Hong Kong $^{20}$ and only $4 \%$ in Malaysia. ${ }^{21}{ }^{22}$ In our region, the Middle East, little is known about how prevalent falling is among the elderly. One study conducted in Qatar showed that prevalence was almost the same as global studies $(34 \%) .{ }^{23}$ However, in Egypt, the prevalence of falls among the elderly was even higher than our findings $(60.3 \%){ }^{24}$ These differences between countries could be related to different ethnicity and culture-related factors that could play roles in falling among old people. In our sample, $47 \%$ of individuals who had experienced falls had fallen two or more times during the previous 12 months. Our findings were similar to those of an Italian study where $43.1 \%$ of the elderly who had fallen, had experienced more than one fall during a 1-year period ${ }^{25}$ and to an American study that showed a prevalence rate of $54 \% .{ }^{26}$ Previous findings found that fall-related injuries among the elderly ranged from $30.6 \%$ to $73.3 \% .^{10}{ }^{1627}$ This range was not matched in our study where more than $74 \%$ of those who had fallen had fall-related injuries. Of these individuals, $36 \%$ required more than a 24 hours hospital admission.

In the present study, indoor falls were the most common place of falling (83\%), which is similar to the study of Yeong UY $e t a l^{21}$ and a study conducted by Almawlawi $e t a l^{23}$ This was inconsistent with other studies that showed fewer indoor falls. ${ }^{24}{ }^{25}$ The Almawlawi et al found that falls that occurred on the stairs were more common than those that occurred in the bathroom, which is the opposite of our findings. Moreover, $20 \%$ of participants
Table 2 Prevalence of falls over a 12-month period and fall-related characteristics

\begin{tabular}{|c|c|c|}
\hline \multirow[b]{2}{*}{ Variable } & \multirow[b]{2}{*}{ Category } & \multirow{2}{*}{$\begin{array}{l}\text { Total } \\
\mathrm{n}(\%) \\
\end{array}$} \\
\hline & & \\
\hline \multirow{2}{*}{$\begin{array}{l}\text { Experience any } \\
\text { falls within last } \\
12 \text { months }\end{array}$} & Yes & $590(49.9)$ \\
\hline & No & $592(50.1)$ \\
\hline \multirow{5}{*}{$\begin{array}{l}\text { Number of fall(s) } \\
\text { per person }\end{array}$} & 1 & $312(52.9)$ \\
\hline & 2 & 179 (30.3) \\
\hline & 3 & $73(12.4)$ \\
\hline & 4 & $17(2.9)$ \\
\hline & $5+$ & $9(1.5)$ \\
\hline \multirow[t]{6}{*}{ Fracture site } & Hip & $21(21)$ \\
\hline & Arm & $21(21)$ \\
\hline & Rib & $8(8)$ \\
\hline & Spine & $9(9)$ \\
\hline & Leg & 39 (39) \\
\hline & Others & $2(2)$ \\
\hline \multirow[t]{4}{*}{ Place of falling } & In own house & $762(77)$ \\
\hline & $\begin{array}{l}\text { In someone else's } \\
\text { house/hotel/rest house }\end{array}$ & $62(6)$ \\
\hline & $\begin{array}{l}\text { Public place (mosques, } \\
\text { mall, street, park) }\end{array}$ & $146(15)$ \\
\hline & Other/Not specified & $17(2)$ \\
\hline \multirow{6}{*}{$\begin{array}{l}\text { Place of falling in a } \\
\text { house }\end{array}$} & Stairs & $140(17)$ \\
\hline & Kitchen & 64 (9) \\
\hline & Front door step & $168(20)$ \\
\hline & Bathroom & 250 (35) \\
\hline & Bedroom & $116(14)$ \\
\hline & Other/Not specified & $89(11)$ \\
\hline \multirow{4}{*}{$\begin{array}{l}\text { Place of falling in a } \\
\text { public place }\end{array}$} & Mall & $26(17)$ \\
\hline & Masjid & 35 (23) \\
\hline & Street & $50(33)$ \\
\hline & Other/Not specified & $99(66)$ \\
\hline \multirow[t]{4}{*}{ Time of falling } & Morning & $277(28)$ \\
\hline & Afternoon & $295(30)$ \\
\hline & Evening & $229(23)$ \\
\hline & $\begin{array}{l}\text { Cannot remember/Not } \\
\text { specified }\end{array}$ & $192(20)$ \\
\hline \multirow[t]{5}{*}{ Direction of falling } & Side & $308(31)$ \\
\hline & Knees & $131(13)$ \\
\hline & On front & $301(30)$ \\
\hline & Back & $239(24)$ \\
\hline & $\begin{array}{l}\text { Cannot remember/Not } \\
\text { specified }\end{array}$ & $14(1)$ \\
\hline
\end{tabular}

in this study have fallen in a building outside of the house similar to another study conducted in Malaysia. ${ }^{21}$

There were inconsistent results regarding the effect of increasing age on the risk of falling. Many studies 


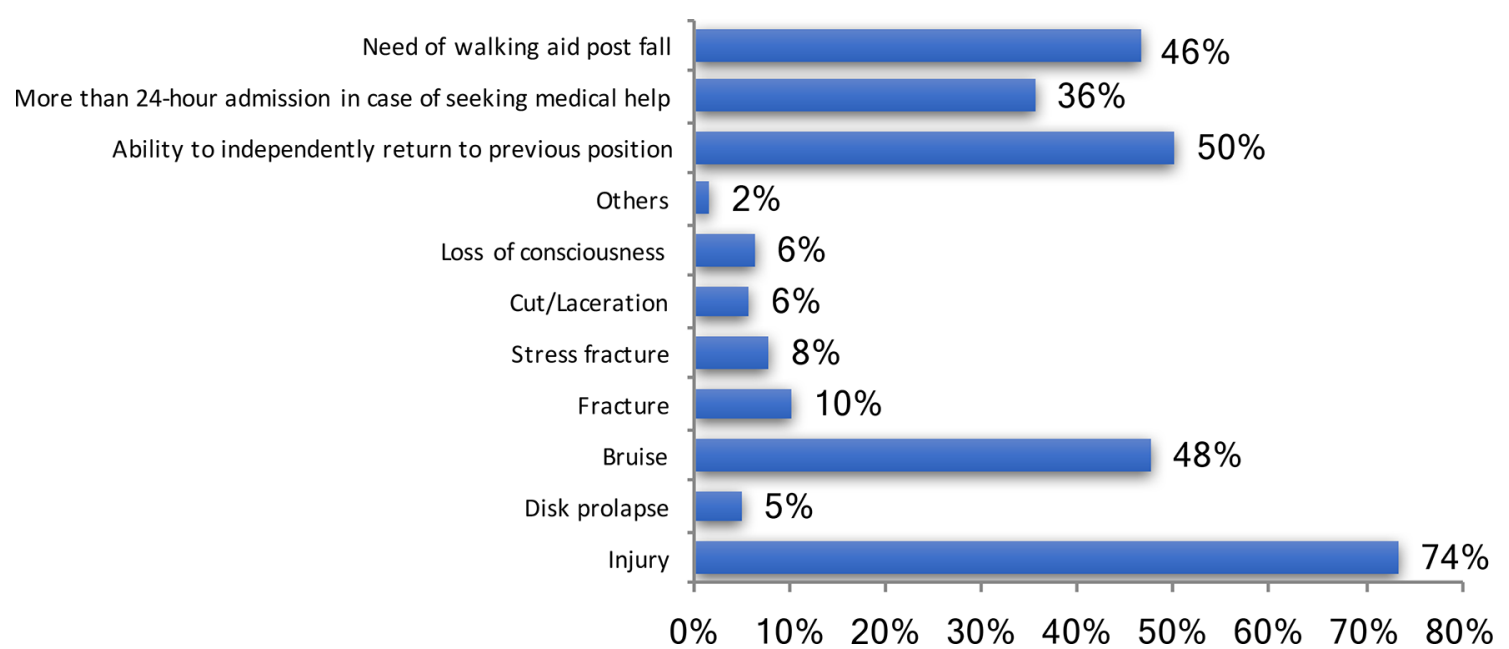

Figure 1 Consequent injuries of falling among elderly Saudis.

reported that falls increase with age. ${ }^{28-30}$ In our study, increasing age was not significantly associated with falls among the elderly. Moreover, gender was not found to be a factor associated with falls, consistent with the findings of a previous study that found a greater association between musculoskeletal pain and trips or falls among the elderly in Japan. ${ }^{19}$ In another study conducted in Germany, the fall rates increased with age in men but not women. ${ }^{31}$ The opposite was found in Nigeria where women were more likely than men to report falls. ${ }^{32}$ These different findings in different countries between elderly men and women could be related to unmeasured biological, social or environmental characteristics.

In comparison with a study undertaken by Kumar A et $a l^{33}$ regarding the effect of lower education levels on increased risk of falling, both studies showed that the risk increased among the uneducated elderly. Marital status, family income and source of financial support were not

Table 3 Forward stepwise univariate logistic regression analysis of the baseline characteristics' predictors of falls among the elderly

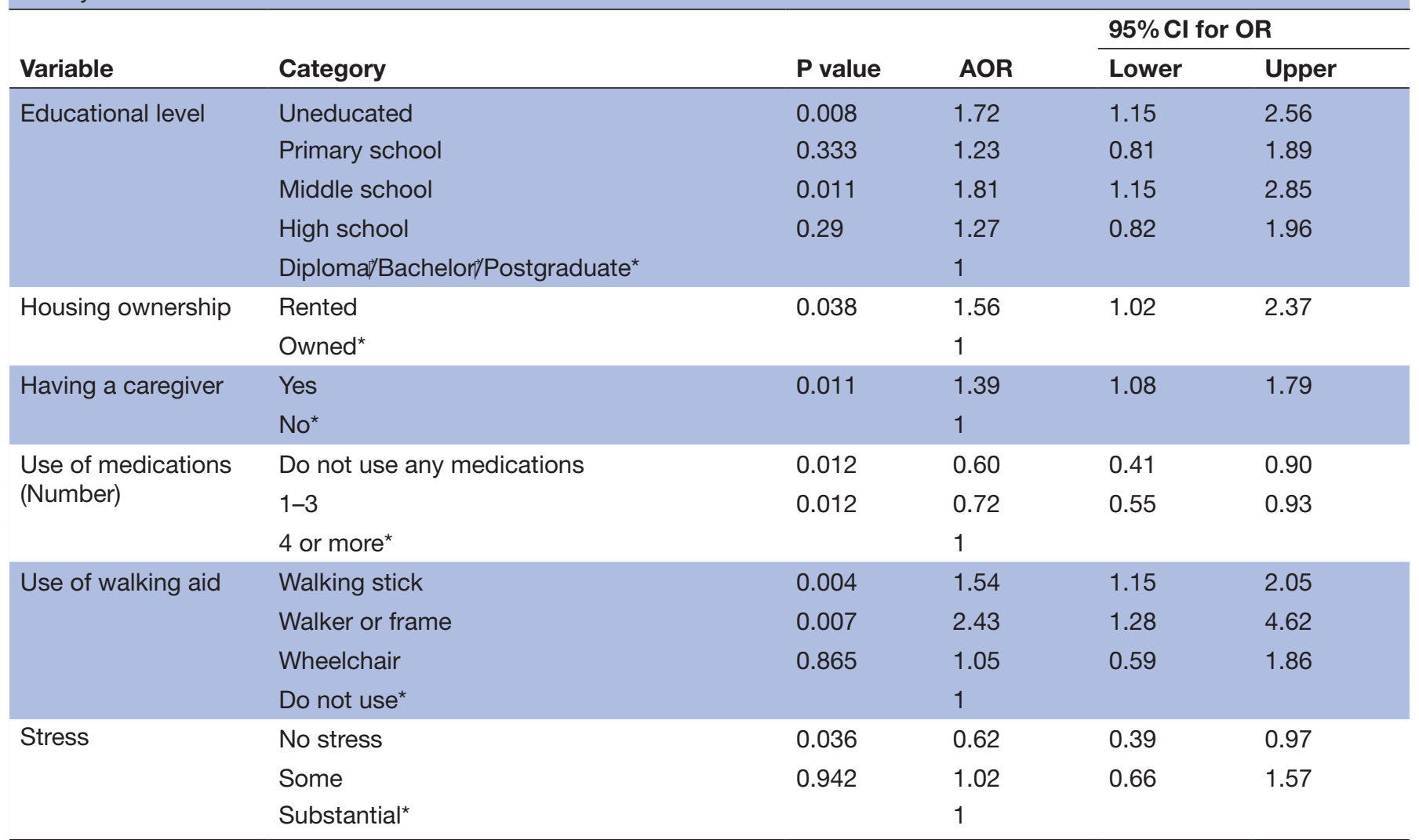

${ }^{*}$ Reference group.

AOR, adjusted OR. 
Table 4 Forward stepwise univariate logistic regression analysis of the predictors of falls (comorbidities and conditions) among the elderly

\begin{tabular}{lllll}
\hline & & & \multicolumn{2}{l}{$\mathbf{9 5 \%}$ Cl for OR } \\
\cline { 5 - 5 } Comorbidity & P value & aOR $^{*}$ & Lower & Upper \\
\hline CVA & 0.019 & 2.75 & 1.18 & 6.43 \\
Osteoporosis† & 0.017 & 1.47 & 1.07 & 2.01 \\
Poor visiont & 0.003 & 1.49 & 1.14 & 1.93 \\
Back pain† & 0.018 & 1.42 & 1.06 & 1.89 \\
\hline
\end{tabular}

*Adjusted OR.

†Not having the comorbidity was the reference group. CVA, cerebrovascular accident. found to be risk factors for falling among elderly people in our study. A study conducted on the risk factors of home injury among elderly people in Malaysia found that fewer married elderly people $(4.9 \%)$ were likely to experience injuries at home than divorced/widowed $(8 \%)$ or single elderly people $(8 \%) .{ }^{22}$ Likewise, the same study reported findings that indicated differences in income do not increase the risk of falls.

Although some studies reported that the use of walking aids protected against falls, ${ }^{34}$ our results, like previous reviews, showed that using a walking aid was associated with a doubled risk of falling among the elderly population. ${ }^{11} 123637$ In the present study, the likelihood of falling

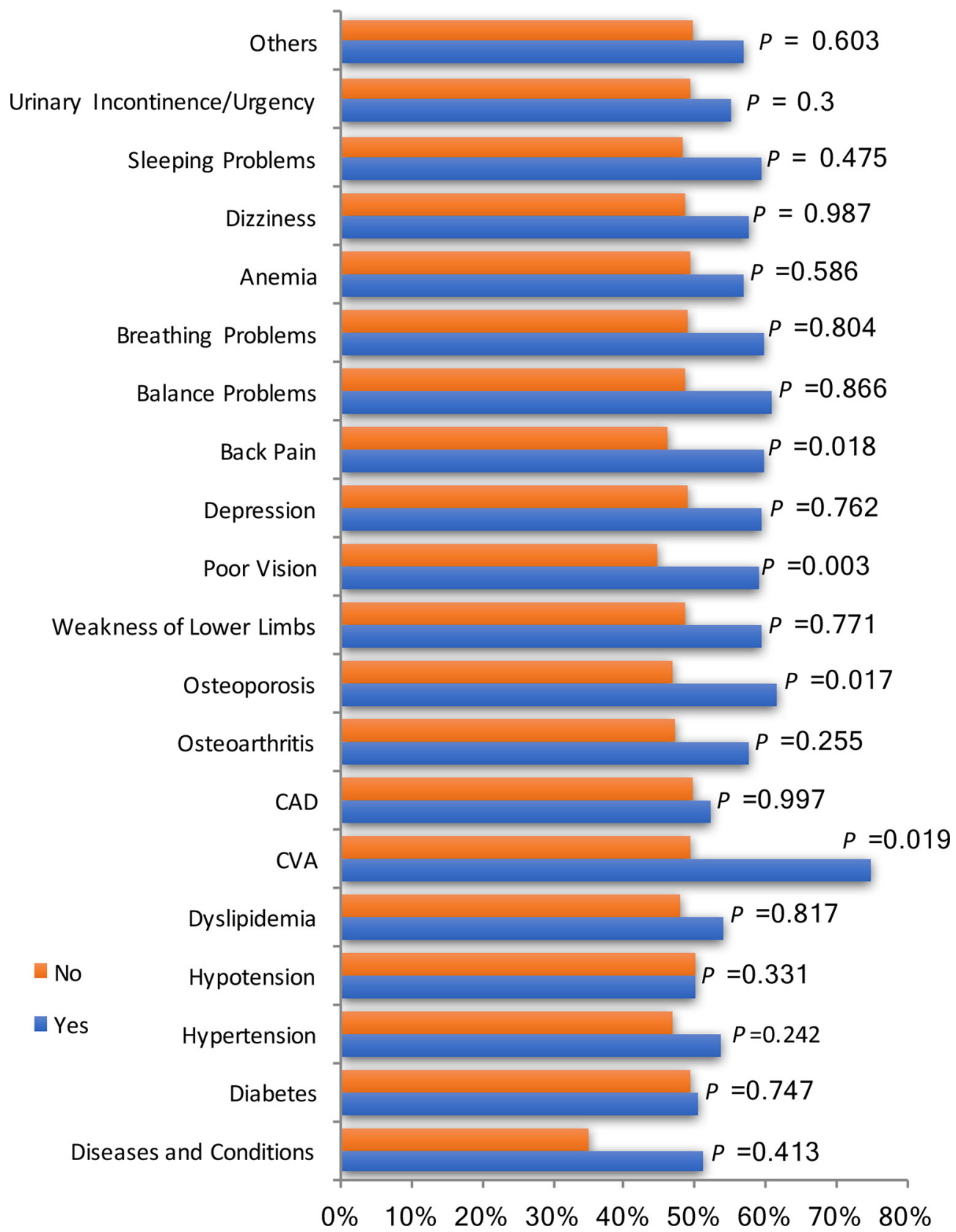

Figure 2 Prevalence of diseases and conditions among elderly Saudis who experienced falls and the relation with falling among the Saudi elderly. ( $P$ is from the univariate logistic regression analysis). CAD, coronary artery disease; CVA, cerebrovascular accident. 
among the elderly was higher with polymedication use. According to almost all studies, the risk of falls increases significantly if more than four medications are taken. ${ }^{38}$ In the literature, stress as a risk factor for falling has not been widely reported. However, one study conducted in Korea found that a higher proportion of those who had fallen reported higher stress than those who had not fallen. ${ }^{39}$ Similarly, our results showed that the elderly who reported 'not having stress' had less risk of falls. As chronic stressors negatively affect physical and mental health, high stress levels surely lead to more falls, especially among elderly people.

Not surprisingly, participants with CVA in this study had a significantly higher risk of falls during a 12-month period. This is consistent with the conclusions of many systematic reviews that show a strong relationship between CVA and increased risk of falls among the elderly. ${ }^{40} 41$ The current study also showed a significant association between osteoporosis and a high risk of falls. This finding agrees with a study conducted in the UK that showed an association between bone density and fall risk. The elderly who had good vision were less likely to experience falls than those with poor vision. This is similar to the findings from Sanjeev et al, who found that the risk of falls among the elderly population has a linear relationship with poor vision. $^{42}$

The present study is the first study in Riyadh to provide an estimation about the prevalence of falls among elderly Saudis and to look at the causes and risk factors underlying these falls. However, this study has some limitations. One is that we did not directly ask the elderly because of the difficulty with older people the research team encountered during the piloting period. Another is that we included all falls during a 12-month period in this study, a period susceptible to a recall bias. In addition, some variables (type of exercise, lift availability, self-evaluation of self-health, vitamin D supplementation and previous specific type of surgeries) were not included in the analysis or listed in the DCF to avoid questionnaire fatigue for the participants and thereby maintain a high retention rate. Self-reported answers may be exaggerated and respondents may be too embarrassed to reveal private details; various biases may affect the results in this study.

\section{CONCLUSION}

This study reveals that there is a high prevalence of falls among elderly Saudis in Riyadh. Falls among this age group are more common in Saudi Arabia than in several other countries. Educational level, housing ownership, presence of a caregiver, number of medications, use of walking aids and stress are associated with an increased risk of falling. Therefore, several preventable risk factors could be addressed by routine geriatric assessment. Increasing awareness about these factors and encouraging regular physical activities are strongly recommended.

Twitter@FaisalAAlhusain
Acknowledgements The authors would like to thank Prof. Ali Hajeer for his help and supervision of this research project.

Contributors FAA, IMA and FYA designed the study, collected data and wrote the manuscript. SLAS, AFA and BIA collected data and wrote the manuscript. EMM analysed and interpreted data. FAA contributed to the interpretation of data.

Funding This research received no specific grant from any funding agency in the public, commercial or not-for-profit sectors.

Competing interests None declared.

Ethics approval The institutional review board of the King Abdullah International Medical Research Center, National Guard Health Affairs, Riyadh, Saudi Arabia.

Provenance and peer review Not commissioned; externally peer reviewed. Data sharing statement № additional data are available.

Open Access This is an Open Access article distributed in accordance with the Creative Commons Attribution Non Commercial (CC BY-NC 4.0) license, which permits others to distribute, remix, adapt, build upon this work non-commercially, and license their derivative works on different terms, provided the original work is properly cited and the use is non-commercial. See: http://creativecommons.org/ licenses/by-nc/4.0/

C Article author(s) (or their employer(s) unless otherwise stated in the text of the article) 2018. All rights reserved. No commercial use is permitted unless otherwise expressly granted.

\section{REFERENCES}

1. UNFPA and HelpAge. Ageing in the twenty-first century: a celebration and a challenge. 2012 https://www.unfpa.org/public/ home/publications/pid/11584

2. WHO Global report on falls prevention in older age. $2007 \mathrm{http} / /$ www.who.int/ageing/publications/Falls_prevention7March.pdf

3. Ambrose AF, Paul G, Hausdorff JM. Risk factors for falls among older adults: a review of the literature. Maturitas 2013;75:51-61.

4. Morisod J, Coutaz M. [Post-fall syndrome: how to recognize and treat it?]. Rev Med Suisse 2007;3:2531-2.

5. Dionyssiotis Y. Analyzing the problem of falls among older people. Int $J$ Gen Med 2012;5:805.

6. Al Senany S, Al Saif A. Assessment of physical health status and quality of life among Saudi older adults. J Phys Ther Sci 2015;27:1691-5.

7. Rubenstein LZ. Falls in older people: epidemiology, risk factors and strategies for prevention. Age Ageing 2006;35(Suppl 2):ii37-ii41.

8. Lord SR, Smith ST, Menant JC. Vision and falls in older people: risk factors and intervention strategies. Clin Geriatr Med 2010;26:569-81.

9. Abusaaq H. SAMA working paper: population aging in Saudi Arabia. 2015 http://www.sama.gov.sa/en-US/EconomicResearch/ WorkingPapers/populationaging in saudi arabia.pdf

10. Stewart Williams J, Kowal $\mathrm{P}$, Hestekin $\mathrm{H}$, et al. Prevalence, risk factors and disability associated with fall-related injury in older adults in low- and middle-incomecountries: results from the WHO Study on global AGEing and adult health (SAGE). BMC Med 2015;13:147.

11. French $D D$, Werner DC, Campbell RR, et al. A multivariate fall risk assessment model for VHA nursing homes using the minimum data set. J Am Med Dir Assoc 2007;8:115-22.

12. Deandrea S, Bravi F, Turati F, et al. Risk factors for falls in older people in nursing homes and hospitals. A systematic review and meta-analysis. Arch Gerontol Geriatr 2013;56:407-15.

13. Alsaif $A$, Hafez $E$, Alsenany $S$. The prediction of falls among older people in Saudi Arabia. J American Sci 2012;8:692-700.

14. Gale CR, Cooper $C$, Aihie Sayer A. Prevalence and risk factors for falls in older men and women: the english longitudinal study of ageing. Age Ageing 2016;45:789-94.

15. Do MT, Chang VC, Kuran N, et al. Fall-related injuries among Canadian seniors, 2005-2013: an analysis of the Canadian community health survey. Health Promot Chronic Dis Prev Can 2015;35:99-108.

16. Orces $\mathrm{CH}$. Prevalence and determinants of falls among older adults in Ecuador: an analysis of the SABE I Survey. Curr Gerontol Geriatr Res 2013;2013:1-7.

17. Stevens JA, Ballesteros MF, Mack KA, et al. Gender differences in seeking care for falls in the aged Medicare population. Am J Prev Med 2012;43:59-62.

18. Fang $X$, Shi $J$, Song $X$, et al. Frailty in relation to the risk of falls, fractures, and mortality in older Chinese adults: results from 
the Beijing longitudinal study of aging. J Nutr Health Aging 2012;16:903-7.

19. Kitayuguchi J, Kamada M, Okada S, et al. Association between musculoskeletal pain and trips or falls in rural Japanese communitydwelling older adults: a cross-sectional study. Geriatr Gerontol Int 2015;15:54-64.

20. Chu LW, Chi I, Chiu AY. Incidence and predictors of falls in the Chinese elderly. Ann Acad Med Singapore 2005;34:60-72.

21. Yeong UY, Tan SY, Yap JF, et al. Prevalence of falls among community-dwelling elderly and its associated factors: a crosssectional study in Perak, Malaysia. Malays Fam Physician 2016;11:7-14.

22. Lim K, Jasvindar K, Normala I, et al. Risk factors of home injury among elderly people in Malaysia. Asian J Gerontol Geriatr 2013;8.

23. Almawlawi E, Alansari A, Ahmed A. Prevalence and risk factors for falls among the elderly in primary healthcare centers (PHC) in Qatar. Qatar Med J 2011;20:1.

24. Kamel MH, Abdulmajeed AA, Ismail S-S. Risk factors of falls among elderly living in urban Suez--Egypt. Pan Afr Med J 2013;14:26.

25. Mancini C, Williamson D, Binkin N, et al. [Epidemiology of falls among the elderly]. Ig Sanita Pubb/ 2005;61:117-32.

26. Biderman A, Cwikel J, Fried AV, et al. Depression and falls among community dwelling elderly people: a search for common risk factors. J Epidemiol Community Health 2002;56:631-6.

27. Cevizci S, Uluocak Ş, Aslan C, et al. Prevalence of falls and associated risk factors among aged population: community based cross-sectional study from Turkey. Cent Eur J Public Health 2015;23:233-9.

28. Bird ML, Pittaway JK, Cuisick I, et al. Age-related changes in physical fall risk factors: results from a 3 year follow-up of community dwelling older adults in Tasmania, Australia. Int J Environ Res Public Health 2013;10:5989-97.

29. CDC Injury Center. Older adult falls, home and recreational safety. 2016 https://www.cdc.gov/homeandrecreationalsafety/falls/index. html.

30. linattiniemi $\mathrm{S}$, Jokelainen $\mathrm{J}$, Luukinen $\mathrm{H}$. Falls risk among a very old home-dwelling population. Scand J Prim Health Care 2009;27:25-30.
31. Rapp K, Freiberger E, Todd C, et al. Fall incidence in Germany: results of two population-based studies, and comparison of retrospective and prospective falls data collection methods. BMC Geriatr 2014:14:105.

32. Bekibele CO, Gureje O. Fall incidence in a population of elderly persons in Nigeria. Gerontology 2010;56:278-83.

33. Kumar A, Carpenter $\mathrm{H}$, Morris $\mathrm{R}$, et al. Which factors are associated with fear of falling in community-dwelling older people? Age Ageing 2014;43:76-84.

34. Graafmans WC, Lips P, Wijlhuizen GJ, et al. Daily physical activity and the use of a walking aid in relation to falls in elderly people in a residential care setting. Z Gerontol Geriatr 2003;36:23-8.

35. van Doorn C, Gruber-Baldini AL, Zimmerman S, et al. Dementia as a risk factor for falls and fall injuries among nursing home residents. $J$ Am Geriatr Soc 2003;51:1213-8.

36. Dhargave P, Sendhilkumar R. Prevalence of risk factors for falls among elderly people living in long-term care homes. Journal of Clinical Gerontology and Geriatrics 2016;7:99-103.

37. Roman de Mettelinge T, Cambier D, Calders P, et al. Understanding the relationship between type 2 diabetes mellitus and falls in older adults: a prospective cohort study. PLoS One 2013;8:e67055.

38. Sousa LM, Marques-Vieira CM, Caldevilla MN, et al. Risk for falls among community-dwelling older people: systematic literature review. Rev Gaucha Enferm 2017;37:e55030.

39. Choi EJ, Kim SA, Kim NR, et al. Risk factors for falls in older Korean adults: the 2011 Community Health Survey. J Korean Med Sci 2014;29:1482-7.

40. Soriano TA, DeCherrie LV, Thomas DC. Falls in the communitydwelling older adult: a review for primary-care providers. Clin Interv Aging 2007;2:545-53.

41. Angelousi A, Girerd N, Benetos A, et al. Association between orthostatic hypotension and cardiovascular risk, cerebrovascular risk, cognitive decline and falls as well as overall mortality: a systematic review and meta-analysis. J Hypertens 2014;32:1562-71.

42. Patel S, Tweed K, Chinappen U. Fall-related risk factors and osteoporosis in older women referred to an open access bone densitometry service. Age Ageing 2005;34:67-71. 